ORIGINAL ARTICLE

\title{
Effectiveness of rugby headgear in preventing soft tissue injuries to the head: a case-control and video cohort study
}

\author{
S J Jones, R A Lyons, R Evans, R G Newcombe, P Nash, M McCabe, S R Palmer
}

Br J Sports Med 2004;38:159-162. doi: 10.1136/bjsm.2002.002584

See end of article for authors' affiliations

Correspondence to: S J Jones, Department of Epidemiology, Statistics and Public Health, University of Wales College of Medicine, Heath Park, Cardiff' CF14 $4 \mathrm{XN}$, Wales, UK jonessj3@cardiff.ac.uk

Accepted

18 February 2003
Objective: To determine if headgear use by rugby players was associated with a reduced risk of head or facial laceration, abrasion, or fracture.

Methods: An emergency department based case-control study in South Wales, UK, with cases being rugby players treated for superficial head and facial injuries and controls being their matched opponents during the game. A review of videos of the 41 games in the 1999 Rugby World Cup was also carried out to compare with the case-control study. Odds ratios (OR) and $95 \%$ confidence intervals $(95 \% \mathrm{Cl}$ ) were used to measure association between exposure (headgear wearing) and outcome (head and facial injuries).

Results: In the case-control study, 164 pairs were analysed, with headgear worn by $12.8 \%$ of cases and $21.3 \%$ of controls. Headgear use was associated with substantial but non-significant reductions in superficial head (OR $=0.43,95 \% \mathrm{Cl} 0.13$ to 1.19$)$ and facial $(\mathrm{OR}=0.57,95 \% \mathrm{Cl} 0.21$ to 1.46 ) injuries. The video study followed 547 players over 41 games, during which there were 47 bleeding injuries to the head. Headgear use significantly reduced the risk of bleeding head injury in forwards $(O R=0.14,95 \%$ $\mathrm{Cl} 0.01$ to $0.99, \mathrm{p}=0.02$ ), but not in backs. There was also a higher risk of facial injury among forwards, but this was not significant.

Conclusions: The combined results suggest that headgear can prevent certain types of superficial head injuries in players at all levels of the game, but the evidence is strongest for superficial head injury in elite forwards. A randomised controlled trial would be the best way to study this further.
$\mathrm{R}$ ugby union is a fast moving collision sport. In Wales, it results in more injuries treated in the emergency department than any other sport, even though soccer has three times the number of players. ${ }^{1}$ In fact, of 13 popular sports played in England and Wales, rugby has been found to carry the greatest risk of injury. ${ }^{2}$

Superficial head and facial injuries-lacerations, abrasions, and fractures-are among the most common rugby injuries, accounting for $14-29 \%$ of all injuries and occurring at a rate of 21.2 per 1000 player games. ${ }^{3-8}$ Lacerations account for 60 $80 \%$ of these injuries and occur at a rate of 10.0 per 1000 player games-double the rate of any other type of injury to the head. ${ }^{49}$

Analysis of trends using the All Wales Injuries Surveillance System (AWISS) showed that numbers of emergency department treated rugby related abrasions, lacerations, and fractures to the head and face fell by $20 \%$ between October and December 1997-1998 and the same period in 1998-1999, whereas injuries to other body parts increased by $10 \% .{ }^{10}$ There were no changes in the number or location of emergency departments during this time. Several of the authors are keen rugby fans and noted a considerable increase in the number of players wearing headgear during Welsh National League games at all levels. This observation was confirmed by retailers reporting sales increases, with similar reports being made by Canadian researchers. ${ }^{11}$

During the 1990s, rugby developed a higher profile and more money became available to those playing the game at the elite level. As a result, players have sought to reduce their risk of injury by using protective padding. ${ }^{5}$ However, a systematic review of the literature failed to find significant evidence to show that such padding prevents injury.

The headgear permitted for use by players is a soft helmet covering the forehead, skull, and ears and fastening under the chin using a velcro strap. Maximum permissible thickness is $1 \mathrm{~cm}$, and additional padding is normally found over the crown of the head. ${ }^{12}$ Headgear is generally believed to prevent lacerations, abrasions, and cauliflower ears, and their use is mandatory in Japan. ${ }^{13}{ }^{14}$ Increased use of face masks on helmets by ice hockey players led to a decrease in facial injuries, but increases in neck and spinal injuries. ${ }^{15}$ Although a distinctly different sport, the experiences of ice hockey and the concerns raised within rugby suggest that further research evaluating the use of headgear to reduce injury risk in rugby players is warranted.

We operate and manage AWISS, and, using data from this system, we generated the hypothesis that increased headgear use may be resulting in reduced numbers of head and facial injuries treated in Welsh emergency departments. The purpose of this study was therefore to determine if headgear use by rugby players was associated with a reduced risk of superficial head or facial injury.

\section{METHODS}

Emergency department based case-control study A case-control approach was designed, with cases being injured players and controls the opponent playing in the same position during the injury game, a method previously used to study injuries to rugby players. ${ }^{16}$

Emergency departments in South Wales were deemed to be the most appropriate location for the study. General practitioners are rarely approached to treat such injuries, and few are available on Saturday afternoon when most of these injuries occur. Some clubs do have team doctors, but they would be likely to suture players from both teams if necessary.

Ethical approval was obtained and it was agreed that players should verbally consent to participate and confirm this by completing the survey form. 
There are eight emergency departments in South Wales. Six were approached to take part in this study and all agreed to participate. Data collection began on 1 October 1999, ran through the 1999/2000 season and from September to December of 2000/2001. Administrative staff and triage nurses were instructed to ask all rugby players attending for the treatment of a superficial head or facial injury, in this case an abrasion, laceration, or fracture, to participate in the study. Those who agreed to participate were provided with a brief survey form, asking for details of playing position, headgear use and for precise location of injury to be indicated on diagrams. The triage nurse added clinical data, including verification of injury location. Information on use of headgear by controls was also collected on this form. The specific brand of headgear was not requested as this could not be verified for controls

Odds ratios (OR) for superficial head and facial injuries, and by playing position, among discordant pairs were calculated, along with 95\% confidence intervals (CI).

\section{Video cohort study}

Video tapes of all 41 games of the 1999 Rugby World Cup were viewed independently by at least two observers. A third observer clarified discrepancies in injury reports. The observers recorded players, replacements, and playing time for each player, along with use of headgear.

Only bleeding head and facial lacerations were recorded because of the difficulty of reliably identifying any other type of injury. Injury rate calculations were based on total playing time during the 1999 Rugby World Cup.

Odds ratios for injured versus non-injured players were calculated, along with 95\% confidence intervals.

\section{RESULTS}

\section{Emergency department based case-control study}

Three of the participating emergency departments collected fewer than nine cases during the first quarter of the study and were excluded. The remaining three emergency departments collected data on 208 cases, an estimated response rate of $75 \%$ when compared with AWISS data over the same period.

Of the 208 cases, 16 were excluded because injuries were sustained during training, and a further two did not enter any information beyond age, sex, and date. Twenty six were excluded because of a lack of control data. Of these, all playing positions were represented, and five were children under 16.

Twenty one $(12.8 \%)$ of the remaining 164 cases reported wearing headgear, and they stated that 35 (21.3\%) of "opposite numbers" wore headgear. The playing position with the highest injury risk was the number 8 (table 1).

Wearing headgear was associated with a reduction in both superficial head (OR $=0.43,95 \%$ CI 0.13 to 1.19$)$ and facial injuries $(\mathrm{OR}=0.57,95 \% \mathrm{CI} 0.21$ to 1.46$)$, but neither reached significance.

\section{Video cohort study}

A total of 547 players from 20 countries played in 41 Rugby World Cup matches and made a total of 1609 appearances. Headgear was worn for 277 appearances (17.2\%). Forty seven bleeding injuries were recorded ( 1 every 0.9 games), with 28 to the head ( 1 every 1.5 games) and 19 to the face ( 1 every 2.2 games). Twenty seven head lacerations $(57.5 \%)$ were to nonheadgear wearers. The $\kappa$ statistic for agreement between observers before the final decision by a third observer was 0.85 . Forwards were more likely to wear headgear, wearing them for $26.8 \%$ of playing time, compared with $6.5 \%$ for backs. Forwards suffered 30 lacerations to the head and face,
Table 1 Cases by playing position and scrum cap use

\begin{tabular}{|c|c|c|c|c|c|c|}
\hline Position & Total & $\%$ & $\begin{array}{l}\% \text { of } \\
\text { team }\end{array}$ & $\begin{array}{l}\% \\
\text { wearing } \\
\text { SC }\end{array}$ & $\begin{array}{l}\text { Standard- } \\
\text { ised injury } \\
\text { ratio }\end{array}$ & $95 \% \mathrm{Cl}$ \\
\hline Number 8 & 19 & 11.6 & 6.7 & 15.8 & 1.7 & 1.04 to 2.72 \\
\hline Centre & 21 & 12.8 & 13.3 & 9.5 & 1.0 & 0.59 to 1.47 \\
\hline Flanker & 25 & 15.2 & 13.3 & 20.0 & 1.2 & 0.74 to 1.69 \\
\hline Full back & 6 & 3.7 & 6.7 & 0.0 & 0.6 & 0.20 to 1.19 \\
\hline Hooker & 12 & 7.3 & 6.7 & 8.3 & 1.1 & 0.57 to 1.92 \\
\hline Lock & 18 & 11.0 & 13.3 & 16.7 & 0.8 & 0.49 to 1.30 \\
\hline $\begin{array}{l}\text { Outside } \\
\text { half }\end{array}$ & 14 & 8.5 & 6.7 & 7.1 & 1.3 & 0.70 to 2.16 \\
\hline Prop & 25 & 15.2 & 13.3 & 12.0 & 1.2 & 0.74 to 1.69 \\
\hline Scrum half & 11 & 6.7 & 6.7 & 0.0 & 1.0 & 0.50 to 1.81 \\
\hline Wing & 13 & 7.9 & 13.3 & 23.1 & 0.6 & 0.32 to 1.02 \\
\hline Total & 164 & 100.0 & 100.0 & & & \\
\hline
\end{tabular}

Standardised injury ratio $=1.70,95 \% \mathrm{Cl} 1.04$ to 2.70 . Of the 164 cases, there were 183 superficial injuries, 104 injuries to the head, defined as the area under the headgear (71 lacerations, 18 abrasions, and 15 others), and 79 to the face (26 lacerations, 23 abrasions, 16 fractures, and 14 others)

SC, Scrum cap.

compared with 17 to backs. None of the backs and only one head lacerated forward was wearing headgear.

Among forwards, headgear use significantly decreased the risk of a bleeding head injury $(\mathrm{OR}=0.14,95 \%$ CI 0.01 to $0.99, \mathrm{p}=0.02)$, but for backs there was no significant change in risk (OR $=0.00,95 \%$ CI 0.0 to $5.60, p=0.6)$. For the two groups combined, the risk of a bleeding head injury was found to decrease significantly (OR $=0.11,95 \%$ CI 0.01 to $0.84, \mathrm{p}=0.03$ ).

However, for facial injuries to forwards there was a substantial, but non-significant, increase in risk of injury associated with headgear use $(\mathrm{OR}=1.94,95 \%$ CI 0.52 to 7.05, $\mathrm{p}=0.32$ ). As none of the headgear wearing backs suffered an injury, the odds ratio was 0 (95\% CI 0.00 to 10.20 , $\mathrm{p}=1.00)$. Combining these groups showed a non-significant $50 \%$ increase in risk of facial injury among headgear wearing players $(\mathrm{OR}=1.50,95 \%$ CI 0.43 to $4.79, \mathrm{p}=0.68)$.

\section{DISCUSSION}

Players purchase or use personal safety equipment in the belief that its use will reduce the probability or severity of an injury, or both. It is important that all such equipment be tested in actual play to see if this is the case.

In both the case-control and cohort studies, wearing headgear was associated with substantial reductions in the point estimates of injury to the areas covered by the headgear. The results were significant at the $5 \%$ level for the cohort study, but only at the $10 \%$ level for the casecontrol study. These results justify the need for further analysis of safety equipment.

Threats to the validity of the case-control study stem principally from the representativeness of cases and controls and the accuracy of reported information. Recruitment of cases was through clerical and nursing staff in the participating department on a fee per case basis. This strategy worked well in three of the six departments where an estimated $75 \%$ of cases were recruited. The three emergency departments that did comply with the study serve the main rugby playing areas of West Wales. Control selection was based on the premise that in any game the likelihood of an injured player attending an emergency department was similar for both teams and therefore non-injured matched opponents could act as controls. Controls were the cases' opposite numbers, and identification required the case to be able to recall whether the matched opponent was wearing headgear during the match in which the injury occurred. We were not able to test the accuracy of this recall and had to 
exclude 26 pairs where cases could not recall, but these exclusions varied by age and playing position. We do not think that a systematic bias in the reporting of opponents' headgear wearing is likely.

The study design excluded those injured that did not attend an emergency department. However, in the United Kingdom, attendance at an emergency department is free and most players with serious injuries will attend. There was no change in the number or location of emergency departments during the study period, and injured controls would have had identical formal treatment options. There is the possibility that some clubs may have informal medical provision available during a game, but it is likely that players from both sides would use such a service.

Threats to the validity of the video study could result from observer bias. However, there is good independent agreement between observers. It is possible that minor lacerations may have been hidden from view and resulted in an overestimate of the protective effect of the headgear. In the case-control study, the only measure of exposure (to headgear) was at the time of injury, whereas in the video study exposure was measured as minutes of play until an injury occurred. The two are not strictly comparable as the skill level of play differed considerably (international versus national and local level).

Elite or highly skilled players have been found to be at greater risk of suffering injury in both rugby and American football. ${ }^{17-19}$ Among rugby players, a direct correlation between standard of play, fitness, and number of injuries has been reported, ${ }^{18}{ }^{19}$ and greater force and skill used by elite or highly skilled athletes has been cited as exaggerating the risk of injury to American footballers. ${ }^{17}$

These factors are likely to have contributed to the difference between the elite and amateur players, but study of the reasons why different players wear headgear is important. Under 15 year old rugby players in Australia reported being more confident and able to tackle harder when wearing headgear, ${ }^{9}$ but these represented the best players in their age group. It is possible that some amateur players wear headgear because they are more cautious.

The cohort study found that forwards suffered $63.8 \%$ of the bleeding head and facial injuries and wear headgear for more than one quarter of total playing time $(26.8 \%)$ as against $6.5 \%$ of backs. Bleeding head injury risk decreased significantly with headgear use $(\mathrm{OR}=0.14)$, but facial injury risk increased $(\mathrm{OR}=1.94)$. These proportions of injuries to forwards are consistent with previous studies reporting that forwards suffer $54.1-60 \%$ of injuries. ${ }^{720}$ It would seem therefore that increasing use of headgear among forwards would have substantial benefits. However, the increased risk of facial injury is a worrying finding. Further analysis of head and facial impacts during contact would be useful to clarify these findings.

Our study did not include the more severe, but rarer, forms of head injury, such as concussion and brain injury. It does seem unlikely that the soft padding used in the headgear could have a profound effect on the dispersal of impact forces. Furthermore, laboratory based biomechanical testing can never truly replicate playing conditions. Case ascertainment of concussion injuries further complicates research in this area. Research has found that currently available commercial headgear does not provide protection against concussion at a junior level, ${ }^{21}$ but verification in this age group and replication of findings in other age groups is now necessary.

The 1995 Rugby World Cup saw 416 players treated by match doctors for 70 injuries, including 19 lacerations, during 55 games. These injuries were ligament injuries (30\%), lacerations $(27 \%)$, and muscle strains (14\%) and were to
Take home message

Protective headgear appears to provide some protection against bleeding head injuries, but further trials of injury outcomes, including concussions, and players' behavioural responses to its use are now necessary.

the lower limb (42\%), upper limb (29\%), and face (17\%). The overall injury rate was one injury every 0.8 games, and the laceration rate one every 2.9 games. ${ }^{22}$ In our study, 47 bleeding head or face injuries were seen in just 41 games, an injury every 0.9 games. The 1995 World Cup was considered to have the highest rate of rugby injury yet recorded. ${ }^{22}$ Our data, although not complete for all injuries, suggest that the injury rate during the 1999 Rugby World Cup far exceeds this.

The primary concern of many people about lacerations suffered during match play is the risk of transmission of blood borne disease. A study of HIV transmission during professional American football found such a risk to be remote-that is, less than 1 per million games. ${ }^{23}$ A case of seroconversion has been reported in a previously healthy soccer player in Italy, where a "clash of heads" between the healthy player and an injecting drug user known to be HIV positive resulted in both players bleeding heavily. ${ }^{24}$ There is no other evidence of transmission of HIV, or, indeed, hepatitis B, during sport. ${ }^{24}$ Of greater concern should probably be the potential for "dirty" wounds to become infected; in recent years, two Scottish rugby players and one soccer player developed tetanus as a result of cuts acquired during play. Only one of them survived. ${ }^{24}$

In the United Kingdom, the burden of treating the initial injury and any subsequent complications is substantial. Each emergency department attendance alone is estimated to cost the NHS $£ 65.25$

The British Medical Association has recently called for urgent formal trials of injury prevention actions for which there is no current evidence of effect. ${ }^{26}$ This study highlights the difficulties of measuring the effectiveness of protective equipment in observational studies. A large randomised controlled trial of the impact of headgear on injury risk in both amateur and elite players is now necessary. Such a trial is likely to be difficult for a variety of reasons, including informed consent and the imposition of equipment on either individual players or teams, but is now obviously necessary to study this area further.

\section{Authors' affiliations}

S J Jones, R A Lyons, R G Newcombe, S R Palmer, Department of Epidemiology, Statistics and Public Health, University of Wales College of Medicine, Cardiff, Wales, UK

R Evans, Emergency Unit, University Hospital of Wales, Cardiff

P Nash, Local Accident Unit, Neath General Hospital, Neath, Wales, UK M McCabe, Accident and Emergency Unit, Morriston Hospital,

Swansea, Wales, UK

\section{REFERENCES}

1 Sports Council for Wales. Sports participation and club membership in Wales 1995/1996. Cardiff: Sports Council for Wales, 1996.

2 Nicholl J, Coleman P. Acute sports injuries: way in which sports are played is important factor in injury. BMJ 1996;312:844-5.

3 Finch C, Best J, Mclntosh A, et al. Research report: preventing rugby union injuries. Melbourne: Department of Epidemiology and Preventive Medicine, Monash University, June 2002

4 Marshall SW, Waller AE, Dick RW, et al. An ecologic study of protective equipment and injury in two contact sports. Int J Epidemiol 2002;31:587-92.

5 Gerrard DF, Waller AE, Bird Y. The New Zealand Rugby Injury and

Performance Project II. Previous injury experience of a rugby playing cohort. Br J Sports Med 1994;28:229-33. 
6 Garraway M, McLeod D. Epidemiology of rugby football injuries. Lancet 1995;345: 1485-7.

7 Ryan JM, McQuillan R. A survey of rugby injuries attending an accident and emergency department. Ir Med J 1992;85:72-3.

8 Bathgate A, Best JP, Craig G, et al. A prospective study of injuries to elite Australian rugby union players. Br J Sports Med 2002;36:265-9.

9 Finch CF, Mclntosh AS, McCrory P. What do under 15 year old schoolboy rugby union players think about protective headgear? Br J Sports Med 2001;35:89-94.

10 Lyons RA, Jones SJ, Kemp A, et al. The development and use of a low-cost injury surveillance system: the All Wales Injury Surveillance System (AWISS). Inj Prev 2002;8:83-6.

11 Pettersen JA. Does rugby headgear prevent concussion? Attitudes of Canadian players and coaches. Br J Sports Med 2002;36:19-22.

12 IRB. www.irfb.com/index.html. Accessed 27 June 2002.

13 Dietzen CJ, Topping BR. Rugby football. Phys Med Rehabil Clin N Am 1999; 10:159-75.

14 Wilson BD. Protective headgear in rugby union. Sports Med 1998;25:333-7.

15 Murray TM, Livingston LA. Hockey helmets, face masks, and injurious behaviour. Pediatrics 1995;95:419-21.

16 Garraway WM, Lee AJ, Macleod DAD, et al. Factors influencing tackle injuries in rugby union football. Br J Sports Med 1999;33:37-41.
17 Schneider RC. Head and neck injuries in football: mechanisms, treatment and prevention. Baltimore: Williams and Wilkins, 1973.

18 Silver JR. Injuries of the spine sustained during rugby. Br J Sports Med 1992;26:253-8.

19 Silver JR. The prevention of spinal injuries in rugby football. Paraplegia 1994;32:442-53.

20 Sharp JCM, Murray GD, Macleod DAD. A unique insight into the incidence of rugby injuries using referee replacement reports. Br J Sports Med 2001;35:34-7.

21 Mclntosh AS, McCrory P. Effectiveness of headgear in a pilot study of under 15 rugby union football. Br J Sports Med 2001;35:167-9.

22 Jokoet I, Noakes TD. A high rate of injury during the 1995 Rugby World Cup. S Afr Med J 1998;88:45-7.

23 Brown LS, Drotman P. What is the risk of HIV infection in athletic competition? In: Program and abstracts of the Ninth International Conference on AIDS, 6-11 June, 1993, Berlin, Germany. Abstract POC213102.

24 Sharp JCM. ABC of sports medicine: infections in sport. BMJ 1994;308:1702-6.

25 PSSRU. Unit costs of health and social care 2000. www.ukc.ac.uk/pssru/.

26 BMA Board of Science and Education. Injury prevention. London: British Medical Association, 2001. 